\title{
AMOR E DINHEIRO: UMA RELAÇÃO POSSÍVEL?
}

\author{
Glaucia Russo*
}

\begin{abstract}
Neste artigo, tentarei compreender em que aspectos a economia monetária modifica ou influencia o amor na modernidade, sem perder de vista que tais relações se inserem em um contexto onde domina o individualismo e as relações mercantis, mas também relações humanas com toda a sua complexidade, contradições e surpresas. Por meio do diálogo com Georg Simmel, em sua discussão sobre dinheiro e a sociedade moderna, e autores como Tönnies, Giddens e Lázaro, problematizamos alguns dentre os variados aspectos presentes nesse debate. Tomamos como pressuposto que amor e dinheiro aparecem em nossa sociedade como polos ao redor dos quais a vida gira e, se, à primeira vista, são representados como elementos antagônicos ou separados, de outro ângulo, são desejos que se complementam. A sociedade do dinheiro, a nosso ver, faz surgir uma nova modalidade de amor: o amor moderno, fabricado, interessado, que não se sustenta sem a base do dinheiro.

Palavras-chave: dinheiro, amor, modernidade, sociedade; comunidade.
\end{abstract}

Sob o signo da economia do dinheiro, tudo é transformado, até mesmo os sentimentos, o amor e a forma de vivenciar as relações afetivas. Neste artigo, tentarei compreender em que aspectos a economia monetária modifica ou influencia o amor na modernidade, ${ }^{1}$ sem perder de vista que tais relações se inserem em um contexto onde domina o individualismo e as relações mercantis, mas também relações humanas com toda a sua complexidade, contradições e surpresas.

Amor e dinheiro aparecem em nossa sociedade como polos ao redor dos quais a vida gira $\mathrm{e}$

* Doutora em Ciências Sociais. Professora e pesquisadora da Universidade do Estado do Rio Grande do Norte.

Av. Prof. Antonio Campos, s/n. Costa e Silva. Cep: 59625620. Mossoro - Rio Grande do Norte - Brasil. Caixa-Postal 70 ghar@ibest.com.br

${ }^{1}$ Esse espaço - tempo, segundo Simmel, é caracterizado pelo predomínio do dinheiro e ele constrói uma sociabilidade marcada pela distância e proximidade, pela indiferença e pela racionalidade. O dinheiro está em estreita relação com o racionalismo, o cálculo e as ações racionais, conduzindo ao intelectualismo, que se constitui na atitude mental exigida pela metrópole. Tal atitude, por sua vez, é um fenômeno moderno, um fenômeno que só é possível na sociedade sob o signo do dinheiro. Para Simmel, o tempo e o espaço são historicamente determinados, ou seja, são significados diferentemente em épocas distintas. Na modernidade, o dinheiro ordena o tempo e o espaço e, consequentemente, influencia o ritmo de vida dos modernos. se, à primeira vista, são representados como elementos antagônicos, ou pelo menos de forma absolutamente separada, de outro ângulo, são desejos que se complementam e, portanto, garantem a felicidade pessoal. Aqui, por meio do diálogo com Georg Simmel, em sua discussão sobre dinheiro e a sociedade moderna, e autores, como Tönnies, Giddens e Lázaro, problematizamos alguns dentre os variados aspectos presentes nesse debate.

Tomo como pressuposto que a ideia e a vivência concreta do amor se modificam sob o signo da economia do dinheiro, predominando fortes traços do individualismo moderno, sem o qual, por mais paradoxal que possa parecer, o amor, tal qual nós o percebemos e vivenciamos, não seria possível em nosso tempo e espaço.

O consumo do amor é uma nova forma de integração do indivíduo no sistema produtivo. Dito de outra forma, o elemento monetário modifica as relações e, na sociedade do dinheiro, ele tem forte influência sobre o comportamento das pessoas, incluindo-se aí a vivência do amor. Mas é preciso também considerar que esse processo é de mão dupla, pois todos os polos se tocam e se influenciam mutu- 
amente. Assim, o dinheiro está sujeito aos valores, humores e reações de homens e mulheres em um determinado tempo, e não lhes é completamente indiferente, embora o seja em grande medida.

O ser humano, como ser cultural, contamina o dinheiro com seus sentimentos, transforma-o em um objeto animado, ama-o, odeia-o, deseja-o, mas, acima de tudo, dá-lhe significados que estão além da sua mera presença material. Homens e mulheres transformam-no em um símbolo da nossa época, com significados e conteúdos diferenciados, tornando inócua qualquer investigação sociológica que não leve em consideração seus aspectos simbólicos, o que significa que nenhuma relação é meramente econômica, pois, se há contato entre seres humanos, uma gama de outros elementos está em jogo.

O sistema capitalista, com o fortalecimento da economia monetária, transformou o homem em força de trabalho e, consequentemente, em mercadoria. Ele passou a ser um objeto comercializável, pois está à venda: sua sobrevivência depende disso. Ao transformar a força de trabalho humana em objeto sujeito a leis mercadológicas, esse sistema reforçou a importância do dinheiro em detrimento do ser humano. Em todos os cantos e recantos da sociedade, as pessoas trocam suas ideias, ideais, força física e mesmo seus corpos por dinheiro.

Estamos diante de uma sociedade dominada nos seus mais diversos aspectos pelo dinheiro, que transforma seres humanos em mercadoria e relações, outrora marcadas pela irracionalidade, e relacionamentos pessoais, em encontros racionais, mas que apostam nos sentimentos, dentre eles especialmente o amor, como forma de resgatar sua humanidade.

O dinheiro não é apenas deus, mas também demônio do nosso tempo. Por ele valores morais são deixados de lado, e o próprio amor, que aparece como uma forma de romper com a frieza e a indiferença que caracterizaria as relações pessoais modernas, especialmente aquelas engendradas na metrópole, é transformada. Vivemos a época de um amor fabricado, interessado, que não se sustenta sem a base do dinheiro.

Em nosso tempo e espaço, vive-se o amor como uma experiência egoísta, individual, que não se sustenta se as pessoas a ele conectadas não tiverem condições cotidianas de sobrevivência, o que, na modernidade, só parece possível pela posse do dinheiro.

Sob o signo do dinheiro, o amor aparece comoa grande solução de que dispomos para enfrentar o isolamento, oracionalismo, o egoísmo, a competitividade e o individualismo exacerbado experimentado na era moderna. No entanto, ele mesmo já foi contaminado por sua lógica e realidade própria, demonstrando que, em sociedade, nenhum terreno escapa ao domínio do dinheiro, mas que ele também não está imune às vivências, necessidades, tensões e relações erigidas pelos seres humanos.

Se o amor se modifica, as práticas sociais que lhe dão sustentação, por sua vez, o ressignificam, mas não o negligenciam ou anulam: ao contrário, ele é uma ideia fortemente presente, tanto no sentido da busca do amor apaixonado ou romântico, quanto no sentido do amor pela família, pelos filhos, ${ }^{2}$ etc.

Nos dias atuais, o dinheiro está altamente implicado na construção da identidade do ser humano. O elemento monetário, ao mediar as relações entre os seres humanos, as transforma, mas também é transformado por elas. No caso específico das relações afetivas, aparece como uma perversão de um valor considerado sagrado. Isso ocorre porque, de um certo ponto de vista, o dinheiro nega o amor que é tido como um valor fundamental em nossa sociedade e pensado como o elemento que caracteriza o que é humano nas relações sociais. Amor e dinheiro aparecem como antagônicos. São como água e óleo, não se misturam. O

${ }^{2}$ Vale salientar que este também é um fenômeno histórico. Segundo Ariès, até o século XV, "Essa família antiga tinha por missão - sentida por todos - a conservação dos bens, a prática comum de um ofício, a ajuda mútua quotidiana num mundo em que o homem, e mais ainda uma mulher, isolados não podiam sobreviver, e ainda, nos casos de crise, a proteção da honra e das vidas. Ela não tinha função afetiva. [...], o sentimento entre os cônjuges, entre os pais e os filhos não era necessário à existência nem ao equilíbrio da família: se ele existisse, tanto melhor" (2006, p.10). Segundo esse mesmo autor, só no final do século XVII e início do século XVIII "a família tornou-se o lugar de uma afeição necessária entre os cônjuges e entre os pais e filhos, algo que ela não era antes" (p.11) 
dinheiro se separa dos afetos e é sentido como algo prejudicial a eles, especialmente no que concerne ao amor, já que ele aparece como a negação dos sentimentos que, pela sua presença, são remetidos a outros planos.

Relacionar sentimentos e dinheiro vai de encontro a tudo que se aprendeu e introjetou sobre esses dois elementos. Socialmente, reafirma-se o discurso social do amor como algo sagrado, e o dinheiro como uma coisa ao mesmo tempo necessária e suja, impregnada por uma dimensão negativa, que não deveria estar ligado a um sentimento tão "puro" como o amor.

O dinheiro, no imaginário social, aparece como o contraponto do amor. Dinheiro e amor são vistos como contrários, como se estivessem em polos opostos, e é preciso dizer, ao mesmo tempo, complementares. $\mathrm{O}$ amor é um sentimento que estaria acima de qualquer interesse monetário, sustentar-se-ia por si mesmo, não necessitaria de justificativas ou coisas concretas para ampará-lo: existiria como uma dádiva para o ser humano.

No entanto, negar a relação entre amor e dinheiro não é somente uma idealização, mas, remete a uma percepção que a nega como construção histórica, social e cultural. Portanto, nessa discussão, é preciso considerar que, em nossa sociedade, fala-se de um entre vários tipos de amor, de uma noção histórica revestida de valores e atitudes legítimos apenas em nossos dias.

Assim, sem negar ou mesmo negligenciar o idealismo que se apresenta por trás dessa noção, para fins de análise, faz-se necessário pensar o amor em um sentido mais amplo, como um mediador de relações sociais que se transformam cotidianamente e cujas modificações repercutem diretamente nas representações e vivências que o cercam.

A noção de amor não é estática, como não o são também as experiências e percepções dos homens e mulheres em relação a ele. E se, como me faz crer Simmel (1986), a sociedade é uma rede de sociações, tecidas incessantemente de tal forma que de qualquer ângulo é possível alcançar qualquer ponto, sentimentos, amor e dinheiro não estão completamente separados, mas aproximam-se em alguns momentos e, ao se tocarem, modificam-se mutuamente. Assim, não posso deixar de ter em conta que, na sociedade onde predominam relações monetárias, o amor assume características peculiares.

Em primeiro lugar, em nosso tempo, o amor está ligado ao eu; ele aparece relacionado ao fortalecimento da individualidade que é característica do moderno e fortemente amparado no desenvolvimento da economia monetária. Em outras palavras, o dinheiro criou as possibilidades para que os interesses individuais se sobrepusessem aos coletivos e, com isso, contribuiu para o surgimento de um tipo específico de amor, como esfera pertencente exclusivamente ao indivíduo.

O eu ama, sente, sofre, chora, ri. Os sentimentos, na era moderna, são remetidos à esfera pessoal. Cada pessoa vivencia individualmente suas dores, alegrias e emoções, e só por uma decisão particular as divide com outras pessoas. Tudo isso parece óbvio, mas não o é. A individualização dos sentimentos e emoções representou uma forte cisão com a ideia de comunidade ${ }^{3}$. Nela, os sentimentos pessoais só eram importantes se remetidos ao grupo, às dores, às alegrias e às necessidades da coletividade, o que dificilmente ocorre nos dias atuais.

Por outro lado, não podemos pensar, mesmo na modernidade, sentimentos e emoções tão somente na esfera do indivíduo. Eles também se relacionam com o social, é claro que de forma diferenciada daquela que ocorria em comunidade, mas, ainda assim, há uma percepção coletiva do que é significado como tristeza, felicidade, angústia, satisfação, amor ou ódio.

Mesmo em uma sociedade marcada pelo individualismo, não é possível falar em nenhum domínio da vida humana desligado do social, do coletivo; até os sentimentos que parecem apenas estar na esfera de pertencimento do eu são referendados pela instância da coletividade. Como nos faz crer Ferdinand Tönnies (apud Miranda, 1995),

${ }^{3}$ Comunidade e sociedade são aqui pensadas a partir das características apontadas por Ferdinand Tönnies em sua dialética da identidade. Ver Miranda (1995). 
não é possível haver, em nenhuma época ou espaço, modelos societários ou comunitários puros. Assim, eles estão em movimento e convivem em uma relação dialética também na modernidade. "Diferentes segmentos do real, ou se quiser, esferas da realidade, possuem o seu ritmo próprio, e isto implica em reconhecer que as diacronias, as simultaneidades, são mais das vezes perpassadas por tensões. Há temporalidades diversas que são contemporâneas.” (Waizbort, 2000, p.176).

Mesmo que não se possa falar em uma sociedade ou comunidade pura, é possível afirmar que vivemos a época da economia do dinheiro e ela, por sua vez, transforma os sentimentos e, dentre eles, o amor. O individualismo está na base das emoções, as quais se baseiam quase que exclusivamente nos interesses pessoais de cada indivíduo em particular, o que implica a necessidade de que os laços comunitários, nos quais os valores coletivos se sobrepõem aos individuais, tenham sido superados, em muitos aspectos. Na sociedade do dinheiro, é o indivíduo que ama ou odeia, deseja ou rejeita outro indivíduo, independentemente do grupo a que pertence. $\mathrm{O}$ amor é vivido como uma experiência pessoal e única, como um sentimento que está na esfera de pertencimento do eu.

Os afetos e os desafetos estão no campo da sociabilidade, das relações humanas, e eles existem nas relações entre seres humanos, mesmo naquelas que têm o dinheiro como mediador. Não há como saber o que vai ocorrer quando seres humanos se encontram, quando corpos se tocam e solidões se aproximam. Mesmo que tudo isso ocorra pela mediação do dinheiro, a dimensão do humano na relação é capaz mesmo de transformar o próprio dinheiro no processo e ser, ao mesmo tempo, modificada por ele.

Na sociedade do dinheiro, paradoxalmente, fala-se muito de sentimentos. A solidariedade, a amizade, a compaixão, dentre muitos outros, estão na ordem do dia, mas nenhum deles é capaz de nem mesmo se aproximar da importância que é atribuída ao amor como elemento primordial, mesmo para a existência da nossa sociedade.

Os sentimentos e emoções são elos impor- tantes para que as pessoas se relacionem umas com as outras. Através deles, relações são erigidas e as pessoas passam, à medida que travam contato e constroem laços afetivos entre si, a ter certa responsabilidade umas com as outras. Nenhuma relação entre seres humanos prescinde de sentimentos e (ou) emoções. Eles sempre estão presentes, seja em sua dimensão positiva, seja na negativa.

Atualmente, em uma sociedade marcada por relações monetárias, movimento, racionalidade e calculabilidade, a retomada de sentimentos como o amor, a solidariedade, o respeito, dentre outros, que alimentam valores considerados positivos, aparece como uma saída para a frieza que caracterizaria o contato entre as pessoas. $\mathrm{O}$ amor, por sua vez, emerge como a grande solução de que dispomos para enfrentar o isolamento, o racionalismo, o egoísmo, a competitividade e o individualismo exacerbado experimentado na era moderna. Ele se configura como uma espécie de saída, a única coisa digna pela qual se pode e deve lutar; o herói, meio e meta do nosso tempo.

O amor é cantado e contado em verso e prosa. Todos os apelos para a existência de um mundo melhor têm-no como sustentáculo. Ele é a justificativa para todas as coisas; é como se sua reafirmação colocasse em xeque os elementos negativos da vida social, trazendo consigo uma gama de valores socialmente apreciados. De uma forma geral, os sentimentos positivos, e o amor mais especificamente, parecem conceder significado a um mundo percebido como desumano, frio e insensível.

Ao mesmo tempo em que quebra com o eu, remetendo ao outro, que é parte de mim, o amor moderno ${ }^{4}$ só se torna possível precisamente pelo rompimento com o nós. A afirmação é paradoxal, mas o amor moderno não pode ser entendido sem

${ }^{4}$ Comumente, há uma necessidade de, ao estudar o amor, tipificá-lo. Uma grande quantidade de autores o faz. Isso ocorre porque o amor não é uno, ele recobre uma gama de sentimentos. Aqui não considero necessário criar uma nova tipificação, já que poderei recorrer a outros autores. No entanto, penso ser importante anotar que utilizarei especificamente o termo amor moderno para me referir ao amor que considero ser característico dos nossos dias, o que não apenas remete para as relações entre homens e mulheres, mas também entre mulheres, homens, mães e filhos, pais e filhos, dentre outros, e possui uma certa racionalidade, dado o seu contato íntimo com a sociedade do dinheiro. 
que se tenha a percepção exata do que isso quer dizer, o que, para mim, torna-se primordial, já que considero ser esse amor, presente em nosso tempo e espaço, um amor contaminado pela lógica do dinheiro.

A noção de amor está em constante movimento, como estão também as experiências e percepções dos homens e mulheres em relação a ela. O que significa que, de um lado, cada um de nós, por sua experiência de vida e mesmo pela sua inserção em espaços específicos da sociedade, tem um modo característico de experimentar o amor; por outro, tal forma de vivenciá-lo não está desligada da nossa condição social, do tempo e espaço em que nos situamos e da forma como a sociedade em geral o concebe. Em outras palavras, o amor possui tanto uma dimensão individual, quanto coletiva. Assim, embora seja vivenciado individualmente, é uma construção social, o que significa que a forma como o experimentamos e entendemos é determinada por nossa inserção em sociedade. A relação dialética entre indivíduo e sociedade está presente na maneira como ele é construído e experimentado em nossa sociedade.

A afirmação acima aponta, dentre outros aspectos, para o fato de que tal sentimento não existiu desde sempre. Para que tomasse a forma que hoje tem, foi necessário que a sociedade criasse as condições para isso. Assim, o desenvolvimento da sociedade, em detrimento da comunidade, com sua economia monetária e suas grandes metrópoles, estimulou a individualidade e a submissão da lógica social à econômica, criando as condições para o desenvolvimento e a vivência de um tipo específico de amor baseado na experiência absoluta do sujeito.

A modernidade, que tem na economia monetária, ou seja, no surgimento do dinheiro, a sua principal característica, é também marcada por um processo de individuação e libertação. Essa liberdade e essa individuação significam uma maior mobilidade, uma separação em relação à comunidade. Esses aspectos formam seu traço típico: a mobilidade, ou seja, a possibilidade de movimento, que é interior (paixões, sentimentos, pensamentos) e ex- terior (laços com os quais se liga e se afasta).

Essa individuação e essa libertação possibilitam o aparecimento e o fortalecimento de um tipo de amor baseado nos interesses pessoais de cada um, o que implica a necessidade de que os laços comunitários, nos quais os valores coletivos se sobrepõem aos individuais, tenham sido superados, em muitos aspectos. No amor moderno, destaca-se o indivíduo.

O amor é vivido como uma experiência pessoal e única. E é ele que está presente em nossas representações: um amor individual, pautado na ideia do eu e do outro, de seres singulares que tomam para si o direito de amar livremente, sem preocupações com as convenções sociais. O amor, assim como o dinheiro, é um ente que possibilita relações, embora, sob o signo do dinheiro, tais relações assumam características bem específicas. Ele liga pessoas, torna-as dependentes umas das outras, cria pequenos coletivos e, assim, colabora para tornar possível a própria existência em sociedade.

A percepção de amor, sob o signo do dinheiro, é modificada; o ideal romântico para o qual um homem e uma mulher, nascidos um para o outro, se uniriam e seriam felizes para sempre, em detrimento de qualquer coisa que pudesse separálos, não é mais suficiente. Em uma sociedade em que a economia monetária está fortemente desenvolvida, não basta apenas amar: é preciso ter condições de sustentar, de arcar com as necessidades do ser amado ou, pelo menos, de colaborar com o próprio sustento.

Para amar, é preciso sobreviver e quase ninguém, em nosso tempo e espaço, o faz sem dinheiro. O dinheiro está ligado ao suprimento das necessidades básicas do ser humano e também das supérfluas. O amor, por outro lado, também está relacionado a um tipo específico de necessidades humanas, aquelas ligadas ao espírito. O dinheiro aparece como o alimento do corpo, o amor, do espírito, podendo também, em algumas situações, trocarem de lugar um com o outro. Eles aparecem como elos complementares da cadeia.

Em nossos dias, o amor está mais e mais ligado ao dinheiro. Segundo Simmel, as razões do 
amor situam-se num nível bem diferente do próprio amor e, tão logo o amor aparece realmente, elas são introduzidas afetivamente com a totalidade do ser numa categoria totalmente nova em relação à que ocupariam se o amor estivesse ausente. O amor é uma categoria primordial, não tem outro fundamento além de si mesmo. Está completamente intrincado no seu objeto e não simplesmente associado a ele: o objeto do amor não existe antes dele, mas apenas por intermédio dele.

Na sociedade moderna, não é possível viver de amor, salvo se o tomamos como uma mercadoria a ser comercializada. Para sobreviver, é preciso ter dinheiro e certo conforto; ninguém ou quase ninguém quer ou pode abrir mão disso. Ama-se porque se pertence ao mesmo grupo social, se tem os mesmos anseios ou se representa o outro de acordo com uma imagem pré-estabelecida.

O ser amado real é diferente da representação do ser amado. Uma simples parte do ser, embora reconhecida como um e o mesmo, pode se tornar um objeto para nós de diferentes maneiras: como um objeto de representação e como um objeto de desejo. No primeiro caso, criamos uma imagem a partir de alguns elementos reais e outros que fazem parte do conjunto dos nossos anseios, e encaixamo-lo nela. O ser amado é idealizado no processo de amar, mas a imagem precisa corresponder ao real, pelo menos em alguns aspectos. No segundo caso, aspiramos à pessoa, nós a queremos e a desejamos não apenas no sentido sexual, mas por inteiro.

Constrói-se o outro como ser amado e idealiza-se sua imagem a partir de uma pré-existente. Por meio do amor, dá-se forma ao existente. A imagem do ser amado já existe e é modificada em sua determinação qualitativa. O ser humano que eu contemplo e conheço é mais e mais um produto particular. O amor cria o seu objeto como produto totalmente original, mas é preciso que o ser humano exista e seja conhecido, antes de ser amado.

O outro é “meu amor”, com tanta razão quanto é "minha representação"; não é um elemento invariável que entraria em todas as configurações possíveis e, portanto, na situação de ser amado, ou ao qual viria acrescentar-se de certa forma o amor, mas um produto original e unitário que não existia antes. (Simmel, 1993, p.124)

O amor deixa para trás todas as particularidades do amado que estiveram na sua origem. Ele aparece como uma busca, uma tentativa. Buscamos o outro em nós, em nosso próprio sentimento, e construímos uma imagem que, na maioria das vezes, não corresponde ao ser de carne e osso que deveríamos amar. Construímos uma representação do outro e, nela, jogamos as nossas próprias necessidades, desejos e também os elementos corroborados socialmente. Segundo Lins

Nós nos apaixonamos por uma imagem que construímos com base naquela pessoa; de maneira mais específica, penso eu, por uma imagem construída sobre aquele determinado aspecto da pessoa do qual temos forte necessidade. (2007, p.104).

Isso ocorre em diversos níveis e poderia ser representado pela ideia da princesa ou príncipe dos contos de fada, ${ }^{5}$ que encarnam em si a perfeição. Assim, as pessoas constroem uma imagem e, ao se depararem com as pessoas reais, encaixamnas nela, de forma que sua figura se torne o mais próximo possível da representação que criaram.

O amor cria um outro, ou melhor, as pessoas que amam procuram criar uma imagem do ser amado que esteja de acordo com aquilo que é requerido tanto social quanto individualmente, e tal imagem passa tanto pelos atributos relacionados à personalidade, como também pelos traços físicos.

Amor e dinheiro, não estão, portanto, tão distantes um do outro, mas, ao contrário, têm diversos pontos convergentes. Ambos criam e mediam relações, inspiram certa atmosfera de poder pessoal e ou social. Assim, é possível afirmar que, em alguns aspectos, aparecem como complementares.

\footnotetext{
Segundo Lins, nos romances dos contos de fada, a mulher é desejada e recebedora do desejo masculino. Ele é o agente, ela espera e recebe. No caso da mulher, a vida "real" "começa com a chegada do homem que vai amá-la dessa maneira especial. A recompensa por ser uma mulher 'real' não é uma vida real, mas o 'verdadeiro amor', ou seja, a proteção contra a vida real (Nenhuma heroína romântica arquetípica leva uma vida normal e interage ativamente no mundo; ela sempre vai para o castelo, e nunca mais se sabe dela)." (2007, p.106).
} 
De um lado, amor sem dinheiro é quase impossível de ser vivenciado, porque esbarra em impossibilidades materiais que tornam a sobrevivência e a manutenção da relação complicada. De outro, apenas a posse do dinheiro deixa o que se poderia chamar de um vazio existencial, que culmina em uma busca incessante por amor. A relação entre dinheiro e sentimento é não apenas complexa, mas também contraditória, pois, de um lado, o dinheiro esvazia-o, retira dele o seu idealismo, torna-o interessado e interesseiro, e, por outro, o sentimento, de certa forma, humaniza o dinheiro, dá-lhe um sentido que vai além do mero ter e passa pela construção de uma dimensão humana.

À medida que a sociedade moderna avança, dinheiro e sentimento vão se impregnando um ao outro e se tornando os dois grandes objetivos da vida humana. O amor é o que se pode considerar o maior dos sentimentos, mas ele não se sustenta quando descolado da dimensão material. O dinheiro, por sua vez, também precisa do complemento do amor. O dinheiro, em si somente, satisfaz a poucos, completa-se quando relacionado ao amor. ${ }^{6}$

O amor ainda é, em nossos dias, compreendido pela sociedade abrangente como o mais sublime dos sentimentos, e, por isso, ele é buscado incessantemente por homens e mulheres. O dinheiro, por sua vez, é tido como o mais fundamental objeto para a existência humana e é também incessante o desejo de consegui-lo. No entanto, os dois aparecem como polos opostos: o amor no campo espiritual e o dinheiro no material.

Ambos são tidos como indispensáveis à vida humana e, embora ao menos em nível de discurso, nada tenham a ver um com o outro, apresentam-se como os dois pilares da sociedade moderna. O dinheiro coloca em cena a racionalidade, a indiferença, a automação dos seres humanos; o amor, por sua vez, realiza o processo contrário, reafirma a humanidade de indivíduos despojados

\footnotetext{
${ }^{6}$ Um exemplo interessante dessa complementaridade existente na relação que a grande maioria das pessoas tem com dinheiro e amor são as telenovelas. Se observarmos, todos os enredos apresentam como fio condutor, embora existam algumas tramas específicas, a busca incessante por amor e dinheiro, o que parece representar os principais anseios da sociedade em geral.
}

de sua dimensão humana. Então, como dois elementos tão diferentes, e mesmo contraditórios, podem aparecer como complementares e mesmo necessários a um mesmo estilo de vida?

Em primeiro lugar, é preciso afirmar que tanto o amor pelo indivíduo, com as características peculiares do nosso tempo, que aqui estou chamando de amor moderno, quanto o dinheiro, são filhos de uma mesma época e encontraram condições propícias para se desenvolverem mais rapidamente na cidade grande ou metrópole, o que demonstra que a distância entre os dois não é tão intransponível como pareceria à primeira vista.

Em outras palavras, ambos necessitaram do mesmo conjunto de mudanças sociais para que viessem a se tornar tão importantes quanto o são hoje. Os dois são frutos do crescimento da sociedade e da individualidade que tem lugar nela. Ambos exigem que a ideia e a vivência do indivíduo já tenham se afirmado socialmente. ${ }^{7} \mathrm{O}$ amor modificou-se na sociedade do dinheiro e, por isso mesmo, fala-se de amor e dinheiro como realidades complementares.

O amor moderno é um amor interessado, fabricado, e está ligado não apenas às necessidades espirituais dos indivíduos, mas também aos imperativos materiais. Na modernidade, amor e dinheiro caminham juntos, e as pessoas, apesar de ainda professarem um discurso idealizado sobre o amor, que é mesmo uma característica dele, em geral, já o aliam ao dinheiro. Para elas especial-

${ }^{7}$ Conforme Russo (2002), a obra de William Shakespeare, Romeu e Julieta, oferece elementos interessantes para a discussão do amor moderno. A peça foi escrita entre os anos de 1595 e 1596, sendo publicada em 1597; em 1599, foi reeditada e revisada pelo autor, ganhando novas cenas. A trama dá-se na cidade de Verona, Itália, em uma época em que o dinheiro já era um elemento forte e havia um grande predomínio da individualidade. A obra de Shakespeare aparece carregada pela contradição entre sociedade e comunidade, indivíduo e coletividade. Há nela uma forte presença da individuação e da racionalidade e, ao mesmo tempo, de núcleos familiares ligados por laços tradicionais. A individuação ameaça a unidade familiar. Há um duelo constante entre o homem individualizado e a comunidade. A obra reage contra a mercantilização da vida. Aqui reside um forte elemento da dialética, pois sua reação já está ela mesma impregnada pelas consequências dessa mercantilização, já que privilegia a emoção a partir da individuação dos sentimentos. Em Romeu e Julieta, o amor do indivíduo é a referência, embora o amor pela família esteja também fortemente presente. O amor aparece como uma oposição à racionalidade monetária, mas já está prisioneiro dela. 
mente, o amor só é possível de se realizar plenamente à medida que lhes possibilita uma vida melhor também do ponto de vista material.

Assim, idealmente, o amor, na sociedade do dinheiro, aparece ligado ao envolvimento com um ser amado em condições de arcar com as necessidades materiais imperiosas à sobrevivência. Na prática, nem sempre isso ocorre.

Assim como o dinheiro, o amor moderno também se relaciona com um universo de possibilidades que, na maioria das vezes, não é capaz de cumprir. Aponta para uma liberdade que envolve inúmeras idealizações, mas que, por si só, não se sustenta materialmente. Oamor tambémé uma promessa. Promessa de uma vida melhor, em que as dificuldades são facilmente superadas; no extremo, é a promessa de um mundo mais justo e igual.

Tais idealizações ainda estão presentes no imaginário social, mas, ao menos nas relações cotidianas entre casais, podem ser reelaboradas; embora as pessoas o busquem constantemente, já não ficam atrelados a relações se não há compensações concretas em suas vivências.

Diante de tal realidade, é preciso perceber que ocorreu uma mudança fundamental no ideal de amor da sociedade, que, em diferentes momentos históricos, já esteve ligado a valores distintos como a honra, a coragem, a força física e, atualmente, dentre outros elementos, parece também estar ligado à competência financeira dos amantes.

Em nossa sociedade, as mulheres, de uma maneira geral, ainda buscam o amor e o homem idealizado como o príncipe encantado dos contos de fada, mas as exigências mudam; ele não precisa ser corajoso e enfrentar a morte ou perigos inenarráveis para salvá-las. Atualmente, ele deve ser capaz de suprir suas necessidades materiais e respeitar seu sentido de independência. Se não o é, o amor é, na maioria das vezes, colocado como um desejo que pode ser adiado: busca-seotrabalhoearealizaçãoprofissional, que passa a ser, também para as mulheres, uma alternativa plausível na luta pela sobrevivência e mesmo na sua afirmação como sujeitos autônomos, seja diante dos companheiros ou companheiras, maridos, namorados ou mesmo membros da família.
No caso dos homens, de um modo geral, anseia-se por uma mulher que alie independência financeira e submissão ao poder masculino, boa mãe e dona de casa, bonita, recatada e apaixonada. Exigese da mulher que assuma os seus papeis tradicionais de "cuidadora", do homem, da casa e dos filhos e, ao mesmo tempo, colabore com o seu próprio sustento e da família. Aumentam-se as exigências, sem que isso traga maiores compensações do ponto de vista do seu espaço ou poder no âmbito social. Os homens, de uma forma geral, não procuram mais as princesas apáticas dos contos de fada, pois têm outras exigências, não querem mais sustentar sozinhos a casa e as mulheres. Dividem as obrigações, mas resistem em dividir o poder.

O sentido utilitário do amor está presente nas novas exigências para os homens e mulheres na família. A despeito de, na sociedade, predominar a referência a um tipo de amor idealizado, uma análise mais atenta mostra que a ideia de amor já está impregnada pelo sentido do dinheiro.

Trata-se do amor moderno, um amor racional, societário, pautado no individualismo e também numa atitude calculista, mas no qual há diversos fatores idealizados, que, inclusive, algumas vezes, negam ou entram em contradição com os elementos acima elencados. Um amor que quer ser desinteressado, mas não se sustenta e não cumpre suas promessas.

Assim como a representação do ser amado é diferente do ser amado concreto, a representação do amor, o discurso que é professado e reforçado sobre suas características, também é diferente daquele sentimento experimentado no dia-a-dia, cercado de limites, carências e, principalmente, vivenciado por homens e mulheres com histórias, necessidades e personalidades diferenciadas e que, como tal, o constroem de acordo com suas próprias experiências.

$\mathrm{O}$ amor ideal refere-se a um conjunto de elementos que estão respaldados pelo universo do coletivo, e o amor real, embora também esteja balizado em tais elementos, não pode ser separado da vida cotidiana de cada um, das suas histórias e, principalmente, não está descolado do gênero a que pertencem. 
Assim, de acordo com as ideias que estou defendendo aqui, amor e dinheiro estão mais próximos do que é possível imaginar. E, diferentemente do que se poderia pensarà primeira vista, amor e sexo podem ou não caminhar juntos, nem sempre têm relação. São diferentes e podem ser vividos separadamente. No caso das mulheres, tal relação pode mesmo significar uma armadilha, para aquelas que, por meio dessa ligação, aprisionam a vivência do sexo e, em alguns casos, por que não dizer, da sua sexualidade, à existência ou não do amor.

Os homens, ao contrário, aprendem a separar essas duas dimensões, pois, em muitas das suas relações, fazem ou buscam sexo, mas não amor. O amor, quando referido aos companheiros e companheiras, tem o sexo como um dos seus componentes, mas não se assenta nele: encontrase em outra dimensão.

Durante quase toda a sua vida, ele aprende queamore sexo tanto podem ser vivenciados conjunta, quantoseparadamente.Para ogêneromasculino, parece normal amar algumas mulheres efazer sexocom outras; amor e sexo não necessariamente coincidem. Aliás, a dicotomização entre os dois permite aos homens viverem as mais diversas experiências sexuais sem culpas ou ressentimentos, o que, quase sempre, não acontece com as mulheres.

Ao fazer tal afirmação, não gostaria de desconsiderar o conjunto de modificações por que as mulheres vêm lutando e as que conquistaram nos últimos séculos, mas apenas chamar a atenção para o fato de que ainda existem modelos diferentes para homens e mulheres, em nossa sociedade, no que concerne ao sexo e que, apesar de todas as inegáveis conquistas femininas nesse campo, ele ainda é marcado por uma lógica diferente para homens e mulheres.

A opinião corrente alia, erroneamente, instinto sexual a amor. Embora essa ligação não seja tão aparente quanto se imagina, também não é possível afastá-la pura e simplesmente. Amor e sensualidade não se excluem: o que se exclui é amor e sensualidade isolada, pois, ao se colocar o prazer sensual como fim em si mesmo, o amor passa a ser banido do processo.
Nossa emoção sexual desenrola-se em dois níveis de significação. Por trás do arrebatamento e do desejo, da realização e do prazer sentidos, diretamente subjetivos, delineia-se, como consequência, a reprodução da espécie. Dessa atração sexual entre os sexos pode ou não surgir o amor. Mas, ao contrário do que diz o ditado, o amor, ao menos o moderno, não é cego, muito menos desinteressado.

É bom lembrar que o amor inserido no contexto societário está a serviço do indivíduo e é baseado na posse do outro. A afetividade, sob o signo do dinheiro, ganha outra feição. Cada vez mais, em nossa sociedade, nos mais diversos campos, o amor adquire características utilitárias.

O amor moderno está relacionado com as necessidades do indivíduo, é a ele que o amor interessa; o seu sentimento não é mais uma continuidade dos anseios e emoções coletivas, do sentimento do grupo ao qual pertence, como ocorria em nível de comunidade. Ele se descola do grupo e passa a vivenciar os sentimentos a partir da esfera individual. No entanto, o movimento contrário também pode estar presente, pois, à medida que o amor se desenvolve, pode instituir laços entre os envolvidos e possibilitar a criação e a consolidação de um sujeito coletivo, pois tanto a família composta pelo casal, independentemente da orientação sexual, quanto aquela mais ampla, que abarca filhos e até mesmo outros parentes, pode se comportar como um sujeito coletivo, como um núcleo comunitário.

Se assim acontece, o amor tanto está na esfera dos valores comunitários como na dos valores individuais, podendo remeter mais fortemente a um ou outro modelo, dependendo da forma como as relações se engendram. Está aqui posta como possibilidade a ideia dialética de um eterno movimento que vai da sociedade para a comunidade, para depois voltar a ela através das relações constituídas a partir e pelo amor.

Outro aspecto a se destacar em relação ao amor diz respeito a seu caráter sagrado, à possibilidade de unir pessoas eternamente, cujo interesse seria apenas estar e continuar juntas. Atualmente, tal aspecto mostra-se mais fortemente relacionado à transitoriedade; amam-se mais vezes e a 
mais pessoas. Talvez, o ditado popular que mais sirva à nossa época seja aquele que diz: "Quando a necessidade entra pela porta, o amor salta pela janela”. A própria ideia de felicidade, em nossa época, parece estar mais ligada à posse do dinheiro do que ao encontro do amor.

O dinheiro expressa as relações de valor entre os objetos e, ao fazê-lo, os reduz a um ponto de vista quantitativo; ele não faz diferença entre as coisas e valores. Assim, a felicidade e o próprio amor são incorporados a esse processo. O dinheiro muda as relações entre os indivíduos, à medida que os une.

Mesmo partindo da ideia de que essas afirmações são verdadeiras, é interessante lembrar que nenhum fenômeno humano pode ou é tão unilateral. O utilitarismo é a marca do amor sob a égide da economia do dinheiro, mas o idealismo e o romantismo presentes nas noções de amor e afeto ainda estão presentes, ora se interpondo, se superando ou sendo superados.

$\mathrm{Na}$ forma como se configura a sociedade moderna, com seu crescente individualismo, instituições fundamentais da sociedade mudaram, inclusive a família. ${ }^{8}$ Dentre os muitos aspectos modificados nessa instituição particular, gostaria de ressaltar que os pais não mais escolhem a profissão, os amores, o rumo da vida dos filhos. Eles são seres separados e, como tal, são responsáveis por seus próprios atos. A partir dessa lógica, o lar ou a família aparecem, no imaginário social, como espaços onde, mesmo que as discordâncias quanto ao estilo de vida existam, eles são aceitos e amados.

Amor e dinheiro são representados como um ideal de felicidade. Ela só é completa quando os dois são experimentados juntos. É quase improvável falar de felicidade quando se tem apenas um dos dois polos. Pelo menos no que diz respeito à busca de um companheiro ou companheira com quem se quer partilhar a vida e mesmo o amor

${ }^{8}$ Segundo Giddens (2000), em todos os países, há uma grande diversidade de formas de família. A maior parte da vida familiar foi transformada pelo surgimento do casal e da união informal. O casamento e a família são o que se pode chamar de instituição-casca; são chamados pelo mesmo nome, mas dentro seu caráter básico mudou. Hoje, o casal, casado ou não, está no cerne do que é a família, e o amor, somado à atração sexual, tornou-se a base da formação dos laços de casamento. que está ligado às outras esferas da existência, precisa-se do dinheiro para sobreviver ou mesmo para se mostrar digno.

No senso comum, o amor é visto como algo indefinível. Falar de amor nunca implica falar de um conceito, mas de elementos que compõem um tipo específico de afetividade, dos sentimentos e situações vivenciados por cada pessoa particularmente. Nesse sentido, o amor sempre é relatado ou de uma forma idealizada, como algo utópico, que de fato não existe na realidade, ou como sentimentos e sensações experimentados em um determinado momento da vida.

Vivemos a época de um amor fabricado, como se fabricam roupas, armas e pão, para um consumo rápido, repetido e diário. O amor já passou por inúmeras metamorfoses ao longo da história: sob o nome de Eros foi cultuado como um deus na era antiga; foi considerado um mandamento divino, tendo sido professado pela filosofia cristã como o mais importante dos ensinamentos, dentre muitos outros sentidos que lhe foram sendo incorporados; atualmente, é uma mercadoria, amplamente comercializada e consumida em nossa sociedade.

A cultura de massa parece querer nos garantir que é no encontro apaixonado que se pode apreender o sentido e o significado de nossa existência incerta. Desde o momento em que se organiza, ainda em sua fase artesanal do século XIX, a incipiente indústria da cultura especializou-se em falar do amor. Não há problema que seja tratado sem que a questão do amor apareça e acabe por ocupar um papel decisivo no desenrolar na trama narrativa. [...]. Tudo muda e se transforma: só o amor parece permanecer como selo e garantia de nossa humanidade. Pelo amor nos definimos como seres humanos, pelo amor nos humanizamos, e a perda da capacidade de amar equivale à nossa desaparição no indiferenciado mundo dos duplos desalmados. (Lázaro, 1996, p.12-13)

O amor, segundo o autor em epígrafe, é um método ${ }^{9}$ incumbido de oferecer a todos a passagem para um mundo ideal, onde a engrenagem

9 Para o autor em pauta, "a noção de método quer sugerir a ideia de um caminho através do qual se vai a algum lugar, produz-se algum resultado, realiza-se um trabalho. Na tradição que nós elegemos, o amor tem sido pensado como uma passagem, uma maneira de ultrapassar certos limites experimentados e percebidos como determinantes para a condição humana naquele momento. O amor é um método, o que quer também dizer, o amor é uma passagem.” (Lázaro, 1996, p.187). 
social, com toda a sua negatividade, não funciona. O amor ensina a sentir. É preciso ouvi-lo, aprender com ele. Ele aparece como uma solução para o mundo em que vivemos, mas, por outro lado, é uma solução desgastada, pois, além de não realizar efetivamente suas promessas, é utilizado como justificativa para os atos mais dignos e honrados e também para os mais indignos. Ao ser incorporado no dia a dia do ser humano, é ressignificado, adquire novos sentidos e serve para alcançar objetivos diversos. Ele não é apenas um fim, mas um meio e, como tal, nem sempre imprime marcas positivas naqueles em que toca.

Atualmente, ele saiu da esfera dos deuses, é um sentimento humano e está diretamente ligado à necessidade de re-humanizar os indivíduos. É um método pois, por meio dele, mantém-se a esperança no homem, no mundo, em uma vida melhor, embora a forma de vivenciá-lo e senti-lo esteja diretamente ligada às necessidades particulares de cada um. Ele é um fenômeno cuja pluralidade desafia nossa imaginação.

O amor é múltiplo e infindável, camufla-se e metamorfoseia-se para atender aos mais íntimos segredos do ser humano, e isso pode ser percebido nas relações sociais, à medida que diferentes mulheres e homens fabricam um amor possível de ser vivenciado por eles, buscando experimentá-lo e senti-lo de acordo com suas necessidades, com a inserção em uma determinada classe, cultura ou espaço social. Ele precisa caber não apenas nos anseios da sociedade, mas também naqueles dos indivíduos particulares.

Como dever ser, o amor ancora-se no coletivo, nos sentimentos, necessidades e repertórios sociais ${ }^{10}$, mas, como vivência individual, entram em jogo os elementos singulares da vida de cada

\footnotetext{
${ }^{10}$ Segundo Douglas (1986), para existir sociedade, é preciso que haja algum pensamento e sentimento parecido entre seus membros. Assim, como os seres humanos não são passivos diante do social, ele, por sua vez, não é imune à ação dos indivíduos. Pautando-se no pensamento de Durkheim, ela afirma que "Para ele, o erro inicial é negar as origens sociais do pensamento individual. As classificações, as operações lógicas e as metáforas guiadas são fornecidas ao indivíduo pela sociedade. Acima de tudo, o sentimento a priori de uma rectidão sobre algumas ideias e de absurdo sobre outras é visto como parte do ambiente social." (p.24).
}

um que, ao mesmo tempo, ressignificam e são ressignificados pelo social. As situações que envolvem o amor são diversas, pois nelas se encontram parceiros diferentes e rituais particulares. Cada amor é compreendido como único e singular e é experimentado individualmente, mas também socialmente, pois somos influenciados pelas ideias presentes no imaginário social.

Quando disse anteriormente que as pessoas criam o amor possível de ser experimentado por elas, não poderia esquecer também que esse amor tem um componente social: é o amor possível não só para elas, mas também na sociedade moderna. É o amor do indivíduo, significado por cada um diferentemente, mas através de elementos que remetem ao grupo e à sociedade a que pertence. Desconsiderar isso é perder de vista o amor como construto humano.

Os modernos nem inventaram o amor nem a paixão. Os crimes passionais e os intensos desejos que faziam com que nobres senhores perdessem a cabeça por alguma mulher não eram, nem continuam sendo privilégio das sociedades ocidentais modernas. Sempre houve relações apaixonadas, quaisquer que fossem as noções de dignidade e o status que recebessem nas diferentes épocas históricas vivenciadas pelo ser humano. Pode-se imaginar a princípio que quanto maior a importância que se atribui ao indivíduo, maior peso terá o amor como expressão de sua autonomia.

O amor no mundo moderno torna-se um grande espaço que envolve o corpo, os sentidos, a imaginação, o próprio reconhecimento que o sujeito faz de si. A promessa de experimentar o eu em toda sua intensidade na descoberta do jogo amoroso só é possível quando a identidade deste eu supõe uma auto-referência que descarta as relações sociais que dão ao indivíduo sua posição no mundo (Lázaro, 1996, p.78).

O ser humano é percebido como passivo diante do amor: "não se escolhe quem se ama”. Em um universo desumanizado, o amor aparece como uma promessa e uma esperança de reencantamento, solidariedade eleita contra um mundo adverso. O amor une as pessoas e, como tal, remete à comunidade, ao rompimento com o indivíduo como ser isolado. 
Ao mesmo tempo, o amor moderno oferece consistência ànoção de indivíduo, que se torna o solo onde ele se ancora. Amor e indivíduo, em nosso tempo, ligam-se de forma essencial. À medida que as relações entre indivíduo e sociedade se transformam, que o princípio de utilidade impõe à vida econômica uma lógica que contradiz a lógica social tradicional, que a ruptura com as tradições lança o indivíduo numa situação de desamparo, a noção de amor adquire maior importância, complexidade e vigor.

$\mathrm{O}$ amor vivenciado hoje em dia demonstra o predomínio de um novo estilo de vida, o estilo moderno, no qual os valores societários são fortalecidos em detrimento dos comunitários. $\mathrm{O}$ amor hoje é interessado e está mais relacionado com a individualidade e autonomia de cada um.

Por tudo isso, o casamento ou o relacionamento estável passa a ser percebido como um negócio que pode ser desfeito a qualquer momento, se não trouxer os resultados esperados. No extremo, mora-se em casas separadas e tem-se tempo e espaço determinado para os encontros conjugais. Calculam-se perdas e ganhos e, no balanço final, o indivíduo e seus interesses pessoais são os mais importantes. Quando o relacionamento não mais satisfaz a uma das partes, ele é desfeito e está sempre posta a possibilidade do surgimento de um novo amor. Não está em jogo aqui o "para sempre", presente no amor romântico. ${ }^{11}$

${ }^{11}$ Entendido aqui a partir das características apontadas por Giddens, 1993. ção ao qual se manifestam reservas, indiferença ou mesmo aversão.

Existem amores sem resposta que fazem nossa felicidade e amores correspondidos que nos tornam miseráveis. Dizer que o amor infeliz é o amor sem resposta baseia-se no fato de que vemos a essência do amor na busca de certas coisas exteriores, cuja obtenção nos “torna felizes”. Há uma identificação errônea do "amor feliz" com o amor correspondido.

A ligação entre os seres humanos proporciona o protótipo de inúmeras relações no seio da vida pessoal e interpessoal na sociedade moderna. Segundo Simmel (1990), o ser humano é de essência absolutamente dualista: seu pensamento e vida movem-se numa estrutura bipolar, seus componentes buscam-se eternamente, completam-se mutuamente, sem nunca superar sua oposição. O ser humano depende de outro de quem é separado pelo maior abismo metafísico. É também a imagem mais pura da solidão que faz do ser humano um estranho, não apenas entre as coisas desse mundo, mas também entre os seres que são mais próximos de cada um.

A tensão entre o eu e o tu não aparece em absoluto com a mesma acuidade, quando a motivação é o amor, porque o eu se aproxima afetivamente do tu. "O milagre do amor é justamente não abolir o ser-para-si nem do eu nem do tu, fazer dele inclusive a condição que permite essa supressão da distância, esse fechar-se egoísta em si mesmo do querer-viver." (Simmel, 1993, p.117).

Amor é entrega do indivíduo. Só uma sociedade que atribui ao indivíduo o valor de fundamento e princípio pode compreender por que, então, o amor é a experiência mais intensa. E a intensidade da experiência aumenta à proporção que a entrega é parte da troca. Ora, a sociedade burguesa faz da troca um cálculo, constrói a noção da equivalência universal através do dinheiro, acredita que tudo pode ser medido e pesado, quantificado, e que o indivíduo deve buscar a realização de seus interesses através do lucro pessoal, daa vantagem na troca (Lázaro, 1996, p.200).

O amor aparece, em nosso tempo e espaço, como o refúgio dos ideais de transcendência, felicidade e solidariedade, que a sociedade do dinheiro, paradoxalmente, promete e nega. O discurso amoroso indica ao indivíduo o caminho do Éden, lo- 
calizando o paraíso e a felicidade em seu interior e abstraindo as condições sociais em que isso se dá.

Comumente nos referimos a ele como um assunto da esfera individual, do destino de cada um, mas há um liame tênue e quase imperceptível entre as subjetividades emancipadas e os indivíduos socialmente inscritos. $\mathrm{O}$ etos da intensidade impõe o prazer como obrigação: o cidadão moderno tem o dever de experimentar tudo, buscar prazer e sua satisfação em todas as modalidades e práticas da vida.

A vida não se origina do amor, mas o amor da vida. No percurso que fiz durante a explanação das ideias, procurei mostrar como o amor moderno e o dinheiro são representantes de uma mesma época, embora apareçam em sociedade como polos opostos em um certo sentido e em outros como complementares, não podendo mesmo se sustentar separadamente. Tanto o amor moderno quanto o dinheiro, diferentemente, são produtos da sociedade com seu crescente individualismo e fruto das necessidades humanas. Ambos são mediadores das relações entre os seres humanos, apesar de criarem relações distintas e serem significados e valorados diferentemente no seu âmbito.

A palavra amor e seus derivados são o testemunho mais eloquente das promessas que os homens se fizeram. Torná-lo uma experiência individual, exclusiva, incomunicável, quase impossível, é talvez a única resposta possível para uma sociedade que fez de sua ordem uma violência terrível, social, ecológica e espiritual.

(Recebido para publicação em março de 2010) (Aceito em fevereiro de 2011)

\section{REFERÊNCIAS}

ARIÈS, Philippe. História social da criança e da família. Trad. Dora Flaksman. 2.ed. Rio de Janeiro: LTC, 2006.

BEAUVOIR, Simone. O segundo sexo: a experiência vivida Trad. Sérgio Milliet. Rio de Janeiro: Nova Fronteira, 1980. v.2. BOURDIEU, Pierre. A dominação masculina. Trad. Maria Helena Kühner. Rio de Janeiro: Bertrand Brasil, 1999.

CERTEAU, Michel. A invenção do cotidiano: artes de fazer. Trad. Ephraim Ferreira Alves. Petropólis-RJ: Vozes, 1998. v.1 DODD, Nigel. A sociologia do dinheiro. Trad. Waldivia Marchiori Portinho. Rio de Janeiro: Fundação Getúlio Vargas, 1997.
DOUGLAS, Mary. Como pensam as instituições. Lisboa: Instituto Piaget, 1986 (Coleção sociedade e organizações).

FOUCAULT, Michel. História da sexualidade: à vontade de saber. Trad. Maria Thereza da Costa Albuquerque e J. A. Guilhon Albuquerque. Rio de Janeiro: Edições Graal, 1997. v.1

Microfísica do poder. Organização, introdução e revisão técnica de Roberto Machado. 15.ed. Rio de Janeiro: Edições Graal, 2000.

GIDDENS, Anthony. A transformação da intimidade: sexualidade, amor \& erotismo nas sociedades modernas. Trad. Magda Lopes. São Paulo: UNESP, 1993.

Mundo em descontrole: o que a globalização está fazendo de nós. Trad. Maria Luiza X. de A. Borges. Rio de Janeiro/São Paulo: Record, 2000.

LÁZARO, André. Amor do mito ao mercado. Petrópolis: Vozes, 1996.

LINS, Regina Navarro. A cama na varanda. Arejando nossas ideias a respeito de amor e sexo. Edição revista e ampliada. Rio de Janeiro: Best Seller, 2007.

LOURO, Guacira Lopes (Org.) O corpo educado: pedagogias da sexualidade. Trad. Tomaz Tadeu da Silva. Belo Horizonte: Autêntica, 1999.

MIRANDA, Orlando (Org.) Para ler Ferdinand Tönnies. São Paulo: EDUSP, 1995.

POLANYI, Karl. A grande transformação. As origens da nossa época. Rio de Janeiro: Campus, 2000.

RUSSO, Gláucia Helena Araújo. O amor e a modernidade: um passeio pela sociedade. In: MIRANDA, Orlando Pinto (Org.) Sociabilidades. São Paulo: Terceira Margem 2002. p.71-83.

SIMMEL, Georg. A metrópole e a vida mental In: VELHO, Otávio Guilherme de (Org.) O fenômeno urbano. Trad. Sérgio Marques dos Reis. Rio de Janeiro: Guanabara, 1987. . A ponte e a porta. Trad. Simone Carneiro Maldonado. Disponível em: www.geocities.com./ collegepark/library. Acesso em: 01 dez. 2004.

- Filosofia do amor. Trad. Luís Eduardo de Lima Brandã̃o. São Paulo: Martins Fontes, 1993 (Coleção tópicos).

Philosophy of money. Translate David Frisby and Tom Bottomore. New York: Routledge, 1990.

. Problemas de filosofia de la historia. Buenos Aires: Editorial Nova, 1950.

Simmel. Organização de Evaristo de Morais Filho; Trad. Carlos Alberto Pavanelli et al. São Paulo: Ática, 1983 (Coleção grandes cientistas sociais).

Sociología 2: estudios sobre las formas de socialización. Madrid: Alianza Editorial, 1986.

Sociologie: etudes sur les formes de la socialisation. Trad. Lilyane Deroche-Gurcel et Sibylle Muller. Paris: Universitaires de France, 1999 (Collection sociologies).

SOMBART, Werner. Lujo y capitalismo. Trad. Luis Isabel. Madrid: Alianza Editorial, 1979.

SOUZA, Jessé; ÖELZE, Berthold (Org.). Simmel e a modernidade. 2.ed. Brasilia: UnB, 2005.

WAIZBORT, Leopoldo. As aventuras de Georg Simmel. São Paulo: USP, 2000.

Georg Simmel: sociabilidade e moderno estilo de vida In: MIRANDA, Orlando (Org.) Sociabilidades. São Paulo: LASC, 1996.

WEATHEFORD, Jack. A história do dinheiro. Trad. June Camargo. Rio de Janeiro: Campus/Elsevier, 2005. 


\section{LOVE AND MONEY: A POSSIBLE RELATIONSHIP?}

\section{Glaucia Russo}

In this paper I will try to understand which aspects monetary economy changes or affects love in the modernity, without losing sight that such relationships are embedded in a context where market relations and individualism dominate, but also human relations with all their complexity, contradictions and surprises. Through dialogue with Georg Simmel, in his discussion of money and modern society, and authors like Tönnies, Giddens and Lázaro, we discuss some of the various issues involved in this debate. We take for granted that love and money in our society appear as poles around which life revolves, and if, prima facie, are represented as separated or antagonistic elements, from another angle are complementary desires. The society of money, in our view, gives rise to a new kind of love: modern love, manufactured, interested, that cannot stand without the money base.

Keywords: money, love, modernity, society, community.

\section{AMOUR ET ARGENT: CETTE RELATION EST- ELLE POSSIBLE?}

\section{Glaucia Russo}

Il s'agit, dans cet article, d'essayer de comprendre sous quels aspects l'économie monétaire modifie ou influence l'amour dans la modernité, sans perdre de vue que de telles relations s'inscrivent dans un contexte où ce sont l'individualisme et les relations de marché qui dominent, mais aussi les relations humaines dans toute leur complexité, leurs contradictions et leurs surprises. En dialoguant avec Georg Simmel, dans son analyse concernant l'argent et la société moderne, ainsi qu'avec des auteurs tels que Tönnies, Giddens et Lázaro, nous avons pu poser le problème des enjeux de ce débat. Nous sommes partis du principe que l'amour et l'argent surgissent dans notre société comme des pôles autour desquels la vie s'articule et, s'ils sont d'abord représentés comme des éléments antagoniques ou séparés, vus dans une autre optique, il s'agit de désirs complémentaires. La société de l'argent fait surgir, à notre avis, un nouveau type d'amour : l'amour moderne, fabriqué, intéressé, qui ne peut exister dans être basé sur l'argent.

MotS-CLÉs: argent, amour, modernité, société, communauté.

Glaucia Russo - Doutora em Ciências Sociais pela Universidade Federal do Rio Grande do Norte. Professora e pesquisadora da Universidade do Estado do Rio Grande do Norte. Tem experiência na área de Serviço Social, Sociologia e teatro, atuando principalmente nos seguintes temas: sexualidade, pesquisa social, sociabilidade e dinheiro, Assistência Social , violência intrafamiliar contra crianças e adolescentes e na área de direção cênica e interpretação teatral. Interessa-se, particularmente, pela contribuição teórico-metodológica de Georg Simmel. Publicações recentes: RUSSO, G. H. A. (Org.); RAMOS, S. R. (Org.); QUEIROZ, Fernanda M. (Org.). Serviço Social na contra corrente: lutas, direitos e políticas sociais. 1. ed. Mossoró-RN: Edições UERN, 2010. 216p; RUSSO, G. H. A. ; ASSIS, R. L. M. ; Nogueira, Isiany Aliny de M. ; Oliveira, Luan Gomes dos Santos; SANTOS, Maria José. Velhas notas, canções novas: gestão e controle da Assistência Social em Mossoró. Serviço social na contra corrente: lutas, direitos e políticas sociais. 2010, v. , p. 41-65; RUSSO, G. H. A.; ALVARO, M. C.; BRETTAS, T. Questão social e mediação de gênero: a marca feminina na Assistência Social. Ser Social (UNB), v. 10, p. 129-159, 2008. 